\title{
Определение параметров ионитных комплексов, образующихся при сорбции катионов никеля слабоосновным анионитом АМ-7
}

\author{
Колодяжный В.А., Челнакова П.Н., Мурачева Е.С. \\ Обнинский институт атомной энергетики - филиал федерального государственного автономного \\ образовательного учреждения высшего образования «Национальный исследовательский ядерный \\ университет «МИФИ» ИАТЭ НИЯУ МИФИ, Обнинск
}

Поступила в редакцию 12.02.2018 г.

DOI: https://doi.org/10.17308/sorpchrom.2019.19/653

Исследована сорбция катионов никеля комплексообразующим анионитом АМ-7. Показано, что сорбция ионов никеля из водных растворов удовлетворительно описывается уравнением Ленгмюра, линейная аппроксимация которого позволяет определить максимальную сорбционную емкость комплексообразующего анионита. Для определения характеристик ионитного комплекса - константы устойчивости и координационного числа - рассмотрены два независимых метода: определение константы устойчивости по коэффициенту распределения и методом разрушения аммиачных комплексов никеля при контакте с депротонированной формой ионита. Рассчитанные константы устойчивости ионитных комплексов и значение координационного числа в обоих случаях находятся в удовлетворительном согласовании.

Ключевые слова: слабоосновный анионит, комплексообразование, сорбция катионов анионитами.

\section{Determination of the parameters ionite complexes formed by nickel sorption weak base anion exchangers AM-7}

\author{
Kolodyazhnyi V.A., Chelnakova P.N., Muracheva E.S. \\ Obninsk Institute for Nuclear Power Engineering IATE MEPHI, Obninsk
}

Studied of weak basic AM-7 anionite complexing with nickel cations. It is shown that the sorption of nickel ions from aqueous solutions is satisfactorily described by the Langmuir equation, the linear approximation which allows to determine the maximum sorption capacity of the complexing anion. To determine the characteristics of complex ionite - sorption capacity, stability constants and coordination number - consider two independent methods: determination of stability constants for the distribution coefficient and by the destruction of ammonia complexes of nickel in contact with the deprotonated form of the resin. The calculated stability constants of complexes ionite and value of coordination number in both cases are in satisfactory agreement.

Keywords: weak basic anionite, complexing

\section{Введение}

В качестве современного метода регенерации цветных металлов из сточных вод с успехом используется ионный обмен [1-3]. Традиционно катионы металлов извлекают из растворов с помощью катионитов. Однако в присутствии солей природ- 
ной минерализации обменная емкость катионитов по целевым катионам резко уменьшается, а также затрудняется переработка регенерационных растворов.

Селективное извлечение цветных металлов может быть осуществлено с помощью слабоосновных анионитов [4,5], обладающих электронодонорными группами, способными сорбировать катионы цветных металлов за счет образования координационных связей. При этом присутствие катионов природной минерализации практически не влияет на сорбционную емкость ионитов [5]. При контакте таких ионитов с молекулами и ионами, имеющими вакантные орбитали, происходит сорбция в результате донорно-акцепторного взаимодействия.

Эффективность применения комплексообразующих ионитов для сорбции ионов переходных металлов определяется их физико-химическими свойствами, основными из которых являются: сорбционная емкость, селективность по отношению к извлекаемым катионам, константа устойчивости ионитного комплекса и его структура.

Целью настоящей работы является определение характеристик ионитного комплекса катионов никеля с анионитом АМ-7 с использованием следующих методов:

- определение константы устойчивости по зависимости коэффициента распределения от концентрации свободных координационно-активных групп в фазе ионита;

- определение константы устойчивости при сорбции катионов никеля из его аммиачных комплексов при контакте с анионитом АМ-7 в ОН-форме.

\section{Эксперимент}

Эксперименты по определению координационного числа и константы устойчивости ионитного комплекса заключались в следующем. Точная навеска анионита (1г с точностью 0.0002г), предварительно переведенного в ОН-форму, заливалась раствором сульфата никеля определенной концентрации $\left(\mathrm{C}_{0}\left(\mathrm{Ni}^{2+)}=100-2000 \mathrm{мг} /\right.\right.$ дм $\left.^{3}\right)$ и оставлялась на $\approx 3$ суток, после чего измерялась остаточная (равновесная) концентрация катионов и рассчитывалась статическая сорбционная емкость анионита:

$$
q=\frac{V \cdot\left(C_{0}-C_{h}\right)}{\ni \cdot m},
$$

где $C_{0}$ - концентрация исходного раствора $\mathrm{Ni}^{2+}\left(\right.$ мг/ дм³); $C_{p}$ - остаточная (равновесная) концентрация $\mathrm{Ni}^{2+}\left(\right.$ мг/дм $\left.{ }^{3}\right) ; V$ - объем раствора $\left(\right.$ дм $\left.^{3}\right) ; \ni$ - эквивалентная масса $\mathrm{Ni}^{2+}$, равная 29.35 мг/мэкв; $m$ - масса сухого ионита (г); g - сорбционная емкость мэкв/Г ( экв/кг ) сухого ионита.

Концентрацию ионов никеля в растворах анализировали спектрофотометрическим методом с диметилглиоксимом на СФ-56 [6].

Определение константы устойчивости при разрушении аммиачных комплексов никеля при контакте с анионитом проводилось следующим образом. В водные растворы сульфата никеля $\left(C_{0}\left(\mathrm{Ni}^{2+}\right)=2.68\right.$ ммоль/дм $\left.{ }^{3}\right)$ добавляли аммиак, концентрация которого варьировалась в диапазоне 0.164-9.94 М. В $100 \mathrm{~cm}^{3}$ полученного раствора, содержащего аммиачные комплексы никеля $\left[\mathrm{Ni}\left(\mathrm{NH}_{3}\right)_{6}\right]^{2+}$, добавляли по 0.5г (с точностью 0.0002г) воздушно-сухого анионита АМ-7 в ОН-форме. После установления равновесия (3 суток) в растворе определяли равновесную концентрацию катионов $\mathrm{Ni}^{2+}$. По разности между начальной $C_{0}\left(\mathrm{Ni}^{2+}\right)$ и равновесной $C_{p}$ концентрациями находили количество сорбированного никеля и относили его к 1кг анионита (в уравнении (1) вместо эквивалентной массы Э берется молярная масса никеля - 58.7 г/моль), тем самым находили сорбционную емкость анионита (моль/кг ионита). 


\section{Обсуждение результатов}

Диссоциация ионитного комплекса при достижении равновесия между анионитом и раствором может быть представлена следующим уравнением:

$$
\overline{\mathrm{ML}_{\mathrm{n}}} \rightleftarrows \mathrm{M}+\mathrm{n} \overline{\mathrm{L}}
$$

где M - катионы никеля в объеме раствора; $\overline{\mathrm{L}}$ - свободные координационноактивные группы в ионите; $\overline{\mathrm{ML}_{\mathrm{n}}}-$ ионитный комплекс никеля в объеме анионита; $\mathrm{n}$ - число координационно-активных групп, координируемых катионами никеля при сорбции анионитом. Знак заряда катиона никеля (M) в реакции ( I ) для упрощения опущен.

Координационно-активными группами в анионите АМ-7 являются: $\equiv \ddot{\mathrm{N}}$; $=\ddot{\mathrm{N}} \mathrm{H} ;-\ddot{\mathrm{N}} \mathrm{H}_{2}$. Сорбция катионов никеля обусловлена образованием координационных связей между свободными d - орбиталями катиона металла и электронной парой атома азота в функциональных группах ионита по донорно-акцепторному механизмy:

$$
\equiv \ddot{\mathrm{N}}+\mathrm{Ni}^{2+} \rightarrow[\equiv \mathrm{N}: \mathrm{Ni}]^{2+}
$$

Равновесие, описываемое уравнением ( I ), количественно может быть охарактеризовано константой устойчивости ионитного комплекса:

$$
\overline{K_{y c m}}=\frac{\left[\overline{\mathrm{ML}_{\mathrm{n}}}\right]}{[\mathrm{M}][\overline{\mathrm{L}}]^{\mathrm{n}}}
$$

Концентрация комплекса в объеме анионита $\left[\overline{\mathrm{ML}_{\mathrm{n}}}\right]$ (моль/кг ионита) равна концентрации сорбированного металла $[\overline{\mathrm{M}}]$, которая, в свою очередь, равна сорбционной емкости ионита g (моль/кг ионита). Отношение концентрации катионов никеля в объеме ионита $[\overline{\mathrm{M}}]$ и в равновесном растворе $[\mathrm{M}]$ (моль/дм ${ }^{3}$ ) является коэффициентом распределения $\lambda$, с учетом которого уравнение (2) может быть записано в виде:

$$
\overline{K_{y c m}}=\frac{[\overline{\mathrm{M}}]}{[\mathrm{M}]} \cdot \frac{1}{[\overline{\mathrm{L}}]^{\mathrm{n}}}=\lambda \cdot \frac{1}{[\overline{\mathrm{L}}]^{\mathrm{n}}}
$$

Концентрацию свободных координационно-активных групп в объеме ионита

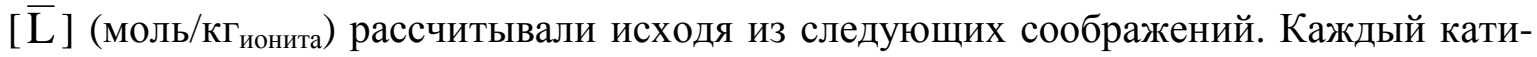
он никеля при сорбции ионитом координирует вокруг себя $\mathrm{n}$ лигандов (координационно-активных групп анионита). Если известна максимальная сорбционная емкость ионита $g_{0}$ и сорбционная емкость $g$ для данной равновесной концентрации никеля в растворе, то концентрацию незанятых (свободных) координационно-активных групп ионита можно рассчитать по разности максимальной и равновесной сорбционной емкости, умноженной на координационное число:

$$
[\bar{L}]=n g_{0}-n g=n\left(g_{0}-g\right)
$$

Подставляя данное значение [ $\overline{\mathrm{L}}]$ в формулу (3), получаем

$$
\overline{K_{\text {ycm }}}=\lambda \cdot \frac{1}{\left(n\left(g_{0}-g\right)\right)^{n}}
$$

Логарифмируя выражение (5), приводим его к виду:

$$
\left.\lg \lambda=\left(\lg \overline{K_{y c m}}+n \lg n\right)+n \lg \left(g_{0}-g\right)\right)
$$

Полученное уравнение в координатах $\lg \lambda=f\left(\lg \left(\mathrm{g}_{0}-\mathrm{g}\right)\right)$ представляет собой прямую, тангенс угла наклона которой дает значение координационного числа $\mathrm{n}$, a отре- 
зок отсекаемый на оси ординат, есть сумма $\left(\lg \overline{\mathrm{K}_{\text {усm }}}+n \operatorname{lgn}\right)$, из которой, зная $n$, определяем $\overline{\mathrm{K}_{\text {усm }}}$.

Для определения максимальной сорбционной емкости экспериментальные результаты по сорбции катионов $\mathrm{Ni}^{2+}$ в зависимости от равновесной концентрации катионов (рис. 1а) были обработаны в координатах уравнения Ленгмюра [7]

$$
g=\alpha C_{p} /\left(1+\beta C_{p}\right)
$$

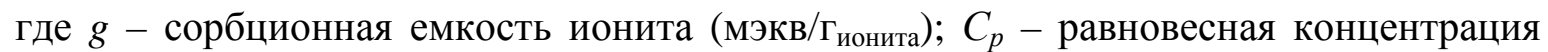
катионов металла в растворе (мг/дм $\left.{ }^{3}\right) ; \alpha, \beta$ - эмпирические константы.

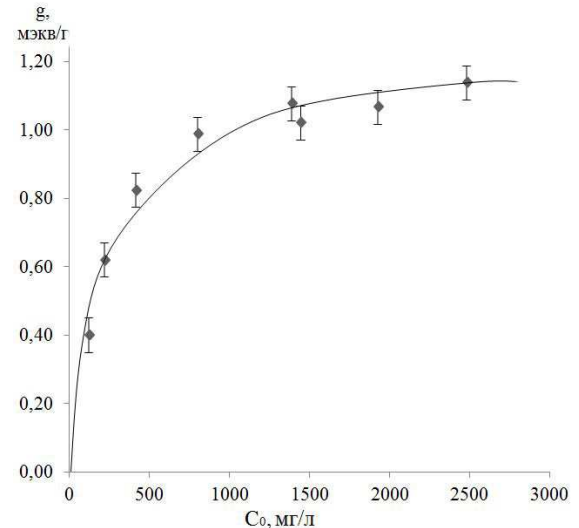

Рис. 1а. Сорбция катионов $\mathrm{Ni}^{2+}$ анионитом АМ-7

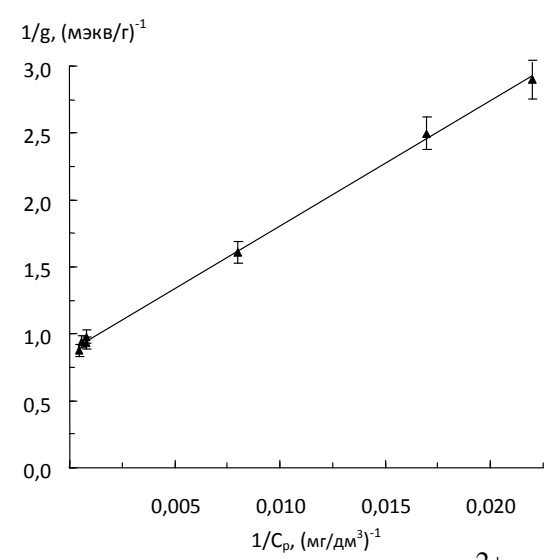

Рис. 1б. Сорбция катионов $\mathrm{Ni}^{2+}$ анионитом АМ-7 в координатах уравнения Ленгмюра

Если сорбция протекает в соответствии с уравнением (7), то экспериментальные результаты должны представлять прямую в координатах $1 / \mathrm{g}=f\left(1 / \mathrm{C}_{\mathrm{p}}\right)$; (рис. 1б):

$$
1 / g=\alpha / \beta+1 / \alpha C_{p}
$$

Рассчитанное из аппроксимации уравнения (8) при $C_{p} \rightarrow \infty$ значение максимальной сорбционной емкости составило $\mathrm{g}_{0}=1.14 \pm 0.13$ мэкв/г. Полученное значение максимальной сорбции удовлетворительно коррелирует с экспериментально полученной величиной $-1.10 \pm 0.12$ мэкв/г. Сопоставление экспериментального и рассчитанного значения сорбционной емкости показывает возможность применения уравнения Ленгмюра для определения максимальной сорбционной емкости анионита АМ-7 при сорбции катионов $\mathrm{Ni}^{2+}$ из водных растворов.

После определения максимальной сорбционной емкости стало возможным обработать экспериментальные результаты также в координатах уравнения (6), (рис. 2). Полученная прямая зависимость показывает, что уравнение (6) с удовлетворительной точностью может быть принято для описания сорбции катионов никеля анионитом АМ-7.

Рассчитанные параметры линейной зависимости соответственно составили: $\mathrm{n}=1.1 \pm 0.1$

$$
\left(\lg \overline{\mathrm{K}_{\text {ycm }}}+\mathrm{nlgn}\right)=2.62 \pm 0.03
$$

Из полученных данных следует, что число координационно-активных групп, координируемых одним катионом никеля, можно принять равным 1. Тогда $\lg \overline{\mathrm{K}_{\text {уст }}}=2.62 \pm 0.03$, соответственно $\overline{\mathrm{K}_{\text {уст }}}=(3.8 \pm 0.3) \cdot 10^{2}, \overline{\mathrm{K}_{\mathrm{H}}}=1 / \overline{\mathrm{K}_{\text {yсm }}}=(2.6 \pm 0.2) \cdot 10^{-3}$.

Рассмотренный метод отличается от предложенного в [4] более простым проведением эксперимента. Отсутствует необходимость определения концентрации не- 
закомплексованных координационно-активных групп ионита потенциометрическим титрованием. Используя экспериментальные данные, только по статической сорбции можно определить как максимальную сорбционную емкость анионита, так и основные параметры ионитного комплекса - селективность (коэффициент распределения), константу устойчивости, координационное число.

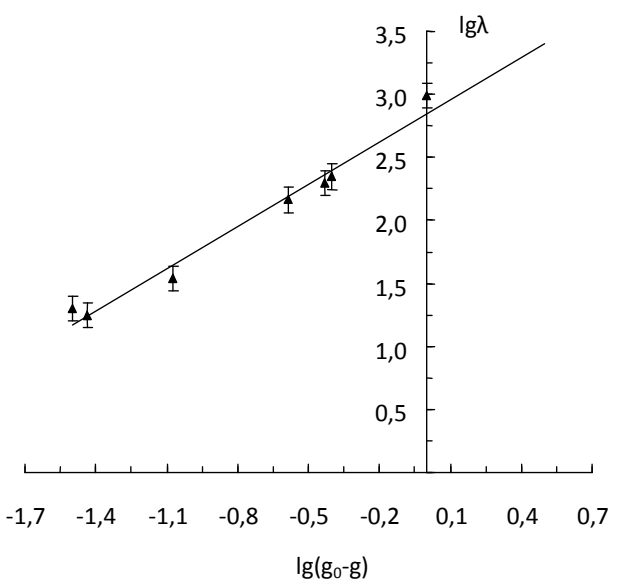

Рис. 2. Зависимость коэффициента распределения от концентрации свободных координационно-активных групп в координатах уравнения (6)

Для подтверждения достоверности полученных результатов характеристики ионитного комплекса никеля были также определены независимым методом. В [4] описано определение константы равновесия ионитного комплекса методом его разрушения при контакте с более сильным донором электронов, чем лигандные группы анионита. Однако, эксперименты по десорбции закомплексованного никеля аммиаком не дали воспроизводимых результатов. Это, вероятно, связано с сопоставимой устойчивостью ионитного и аммиачного комплекса никеля. В связи с этим был рассмотрен обратный метод - разрушение растворенного аммиачного комплекса никеля при контакте с депротонированным анионитом.

Сорбция ионов переходных металлов из растворов их комплексов происходит вследствие обмена лигандов координационной сферы растворенного комплекса на лигандные группы анионита:

$$
\mathrm{ML}_{\mathrm{N}}+\mathrm{n} \overline{\mathrm{L}} \rightleftarrows \mathrm{M} \overline{\mathrm{L}_{\mathrm{n}}} \mathrm{L}_{\mathrm{N}-\mathrm{n}}+\mathrm{nL}
$$

где $\mathrm{ML}_{\mathrm{N}}$ - растворенный аммиачный комплекс никеля, $\left[\mathrm{Ni}\left(\mathrm{NH}_{3}\right)_{6}\right]^{2+} ; \mathrm{ML}_{\mathrm{n}} \mathrm{L}_{\mathrm{N}-\mathrm{n}}-$ анионитный комплекс; $\mathrm{L}, \overline{\mathrm{L}}$ - лиганды растворенного комплекса и анионита соответственно; $\mathrm{N}, \mathrm{n}-$ координационное число в аммиачном комплексе и в анионите соответственно.

Константа равновесия, описываемого уравнением реакции (III), в концентрационной форме определяется выражением:

$$
\overline{K_{p}}=\frac{\left[\mathrm{M}_{\mathrm{n}} \mathrm{L}_{\mathrm{N}-\mathrm{n}}\right] \cdot[\mathrm{L}]^{\mathrm{n}}}{\left[\mathrm{ML}_{\mathrm{N}}\right] \cdot[\overline{\mathrm{L}}]^{\mathrm{n}}}
$$

Умножив числитель и знаменатель уравнения (9) на $\left[\mathrm{ML}_{\mathrm{N}-n}\right]$, получаем:

$$
\overline{K_{p}}=\frac{\left[\mathrm{ML}_{\mathrm{n}} \mathrm{L}_{\mathrm{N}-\mathrm{n}}\right]}{\left[\mathrm{ML}_{\mathrm{N}-\mathrm{n}}\right] \cdot[\overline{\mathrm{L}}]^{\mathrm{n}}} \cdot \frac{\left[\mathrm{ML}_{\mathrm{N}-\mathrm{n}}\right][\mathrm{L}]^{\mathrm{n}}}{\left[\mathrm{ML}_{\mathrm{N}}\right]}=\frac{\overline{K_{y c m}}}{K_{y c m_{n}}}
$$

где $K_{y c m n}$ - константа устойчивости аммиачного комплекса $\left[\mathrm{Ni}\left(\mathrm{NH}_{3}\right)_{6}\right]^{2+}$ по n-й ступени диссоциации:

$$
K_{y c m n}=K_{1} \cdot K_{2} \cdot \ldots \cdot K_{n}
$$


В уравнении (9) примем $\left[\mathrm{M}_{\mathrm{L}_{n}} \mathrm{~L}_{\mathrm{N}-\mathrm{n}}\right] \equiv[\overline{\mathrm{M}}] \equiv g$ - равновесная концентрация катионов никеля, закомплексованных в фазе ионита (моль/кг ионита $) ;\left[\mathrm{ML}_{\mathrm{N}}\right] \equiv[\mathrm{M}]-$ равновесная концентрация аммиачного комплекса никеля в растворе (моль/дм ${ }^{3}$ ); [L] - концентрация аммиака в растворе, изменение которой при установлении равновесия считаем пренебрежимо малым (моль/дм $\left.{ }^{3}\right)$; $[\overline{\mathrm{L}}]$ - концентрация свободных координационно-активных групп в фазе ионита, рассчитываемая по уравнению (4) (моль/кг ионита); $g_{0}$ - рассчитанное ранее значение максимальной сорбционной емкости анионита (0.57 моль/кг ионита). Тогда, логарифмируя уравнение (9), получаем:

$$
\lg \overline{\mathrm{K}_{\mathrm{p}}}=\lg \frac{[\overline{\mathrm{M}}]}{[\mathrm{M}]}+\lg \frac{[\mathrm{L}]^{\mathrm{n}}}{\left(\mathrm{n}\left(\mathrm{g}_{0}-\mathrm{g}\right)\right)^{\mathrm{n}}}
$$

или

$$
\lg \frac{[\overline{\mathrm{M}}]}{[\mathrm{M}]}=\left(\lg \overline{\mathrm{K}_{\mathrm{p}}}+\mathrm{n} \operatorname{lgn}\right)-\mathrm{n} \lg \frac{[\mathrm{L}]}{\left(\mathrm{g}_{0}-\mathrm{g}\right)}
$$

Уравнение (13) является уравнением прямой в координатах $\lg \frac{[\overline{\mathrm{M}}]}{[\mathrm{M}]}=f\left(\lg \frac{[\mathrm{L}]}{\left(\mathrm{g}_{0}-\mathrm{g}\right)}\right)$, из которой по экспериментальным данным можно рассчитать константу устойчивости $\overline{\mathrm{K}_{\text {yсm }}}$ и состав $(\mathrm{n})$ ионитного комплекса.

Экспериментальные результаты представлены на рис. 3. Рассчитанные параметры линейной зависимости составили:

$$
\begin{gathered}
\mathrm{n}=0.9 \pm 0.1 \\
\left(\lg \overline{\mathrm{K}_{\mathrm{p}}}+\mathrm{nlgn}\right)=2.99 \pm 0.08
\end{gathered}
$$

Принимая $\mathrm{n}=1$, получаем $\overline{\mathrm{K}_{\mathrm{p}}}=(1.07 \pm 0.03) \cdot 10^{3}$; тогда с учетом константы нестойкости аммиачного комплекса по первой ступени $\mathrm{K}_{\mathrm{H} 1}\left(\left[\mathrm{Ni}\left(\mathrm{NH}_{3}\right)_{6}\right]^{2+}\right)=1.2[8]$ имеем $\mathrm{K}_{\mathrm{ycmn}}=0.8$ и из уравнения (10) получаем:

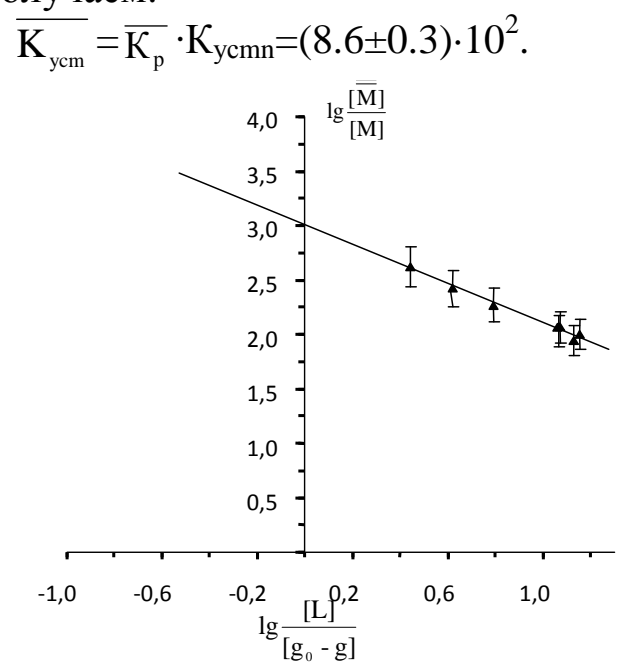

Рис. 3. Сорбция анионитом АМ-7 катионов никеля из его аммиачных комплексов в координатах уравнения (13)

\section{Заключение}

Полученные значения константы устойчивости и координационного числа ионитного комплекса $\left(\overline{\mathrm{K}_{\mathrm{ycm}}}=(8.6 \pm 0.3) \cdot 10^{2}\right.$ и $\left.\mathrm{n}=0.9 \pm 0.1\right)$ удовлетворительно согласуются с ранее найденными величинами (соответственно $\overline{\mathrm{K}_{\text {yсm }}}=(3.8 \pm 0.3) \cdot 10^{2}$ и 
$\mathrm{n}=1.1 \pm 0.1$ ), что позволяет говорить о достоверности полученных результатов и о применимости предлагаемых методов для определения параметров ионитных комплексов.

\section{Список литературы}

1. Цыганков А.П., Лаумянскас Г.А., Балацкий О.Ф., Кержаков В.И. // Хим. пром. 1981. № 1. С. 36-39.

2. Имотоо Йосио, Окада Суко Патент Япония № 55-39393, 1980.

3. Хасимото Ясукино, Накамура Хироси, Ямомото Йосихиде Патент Япония № 5532796, 1980.

4. Салдадзе К.М., Копылова-Валова В.Д. Комплексообразующие иониты (комплекситы). М. Химия. 1980. 336с.

\section{References}

1. Cygankov A.P., Laumjanskas G.A., Balackij O.F., Kerzhakov V.I., Industry \& Chemistry, 1981. No 1, pp. 36-39.

2. Imotoo Josio, Okada Suko Patent Jap. No 55-39393, 1980.

3. Hasimoto Jasukino, Nakamura Hirosi, Jamomoto Josihide Patent Jap. No 55-32796, 1980.

4. Saldadze K.M., Kopylova-Valova V.D. Kompleksoobrazujushhie ionity (kompleksity). M., Khimija, 1980, 336 p.

Колодяжный Владимир Анатольевич - доцент кафедры общей и специальной химии, к.х.н., Обнинский институт атомной энергетики - филиал федерального государственного автономного образовательного учреждения высшего образования «Национальный исследовательский ядерный университет «МИФИ», ИАТЭ НИЯУ МИФИ, Обнинск

Челнакова Полина Николаевна - старший преподаватель кафедры общей и специальной химии, Обнинский институт атомной энергетики - филиал федерального государственного автономного образовательного учреждения высшего образования «Национальный исследовательский ядерный университет «МИФИ», ИАТЭ НИЯУ МИФИ, Обнинск

Мурачева Елена Сергеевна - аспирант кафедры общей и специальной химии, Обнинский институт атомной энергетики - филиал федерального государственного автономного образовательного учреждения высшего образования «Национальный исследовательский ядерный университет «МИФИ», ИАТЭ НИЯУ МИФИ, Обнинск
5. Челнакова П.Н., Колодяжный В.А. // ЖПХ. 2004. Т. 77. № 1. С.78-82.

6. Унифицированные методы анализа вод./ Под общей редакцией Ю.Ю. Лурье. М. Химия. 1971. $375 \mathrm{c}$.

7. Даниэльс Ф., Олберти Р. Физическая химия. М. Мир. 1978. 645с.

8. Гороновский И.Т., Назаренко Ю.П., Непряг Е.Ф. Краткий справочник по химии. Киев: Изд-во АН УССР. 1962. С. 433.

5. Chelnakova P., Kolodyazhnyi V., Russ. J. Appl. Chem., 2004, Vol. 77, No 1, pp. 78-82.

6. Unificirovannye metody analiza vod./ Pod obshhej redakciej Ju.Ju. Lur'e. M., Khimija, 1971, $375 \mathrm{p}$.

7. Daniels F., Alberty R. Physical chemistry M., Mir, 1978, 645p.

8. Goronovskij I.T., Nazarenko Ju.P., Neprjag E.F. Kratkij spravochnik po himii. Kiev, Izd-vo AN USSR, 1962, 433p.

Kolodyazhnyi Vladimir A. - Ph.D. (chemistry), associate prof., department of general and special chemistry, Obninsk Institute for Nuclear Power Engineering IATE MEPHI, Obninsk

Chelnakova Polina N. - senior teacher, department of general and special chemistry, Obninsk Institute for Nuclear Power Engineering IATE MEPHI, Obninsk, e-mail: polincn@mail.ru

Muracheva Elena S. - the postgraduate student, department of general and special chemistry, Obninsk Institute for Nuclear Power Engineering IATE MEPHI, Obninsk 